\title{
Pancreatic Cancer Imaging: What the Surgeon Wants to Know?
}

\author{
Ajaykumar C. Morani ${ }^{1}$ \\ ${ }^{1}$ Department of Radiology, University of Texas MD Anderson Cancer \\ Center, Houston, Texas, United States \\ 2Department of Diagnostic Radiology, University of Texas MD \\ Anderson Cancer Center, Houston, Texas, United States \\ ${ }^{3}$ Department of Anatomic Pathology, University of Texas MD \\ Anderson Cancer Center, Houston, Texas, United States \\ ${ }^{4}$ Department of MBA, IGlobal University, Vienna, Virginia, United \\ States
}

\author{
Address for correspondence Ajaykumar C. Morani, MD, \\ Department of Radiology, University of Texas MD Anderson Cancer \\ Center, 1515 Holocombe Boulevard, Houston, TX 77030, \\ United States (e-mail: amorani@mdanderson.org).
}

J Gastrointestinal Abdominal Radiol ISGAR 2020;3:40-52

\begin{abstract}
Keywords

- pancreatic cancer

- surgeons

- borderline resectable

- malignant IPMN

- malignant pancreatic neuroendocrine tumor

Pancreatic cancer is rare but is one of the deadliest cancers. Complete surgical removal of the cancer with negative margins is the only potentially curative treatment. However, majority of the cases present with distant metastases and/or locally advanced disease, and only a limited subset (up to $20 \%$ ) of patients are surgical candidates. Therefore, accurate staging of pancreatic cancer is very important for treatment planning. It is very important to distinguish between patients who are surgical candidates and those who would need palliative treatment. Imaging plays a crucial role in the detection of the primary tumor, vascular involvement and variants, metastasis, prediction of resectability, and monitoring treatment response. High-resolution multidetector computed tomography $(\mathrm{CT})$ is the primary imaging modality of choice for diagnosing and staging pancreatic cancers. Nevertheless, integration of ultrasound, $\mathrm{CT}$, and magnetic resonance imaging (MRI) may be needed for accurate determination of the tumor extent and optimal management. Herein, we aim to provide a radiological review for "what the surgeon wants to know about pancreatic cancer?" In this review, we highlight the main types of invasive pancreatic cancers and discuss the role of imaging in determining the resectability of pancreatic tumors and the role of neoadjuvant treatment in downstaging borderline or unresectable cases in addition to featuring significant postsurgical complications.
\end{abstract}

\section{Introduction}

Pancreatic cancer accounts for approximately only $3 \%$ of cancers in the United States (12th in incidence order); however, it is one of the deadliest cancers, with a 5-year survival rate of only $8 \% .{ }^{1}$ As per a European cancer epidemiology study in 2017, pancreatic cancer is the fourth most fatal cancer in both men and women. ${ }^{2}$ Around $70 \%$ of patients die within the first year of diagnosis. About 56,770 new cases and 45,750 deaths are estimated to occur due to pancreatic cancer in the United States during 2019. ${ }^{1}$ Complete surgical removal of the cancer with negative margins is the only potentially curative treatment. ${ }^{3}$ However, only a limited subset of patients with localized disease (up to $20 \%$ ) are surgical candidates, as the majority of the patients have distant metastatic and/or locally invasive disease at presentation. ${ }^{4,5}$ Therefore, accurate staging of pancreatic cancer is very important for outlining its treatment approach. ${ }^{6}$

Besides the tumor, node, and metastasis (TNM) staging system (-Table 1), several staging systems and consensus meetings have discussed the staging criteria of pancreatic cancer. ${ }^{7-12}$ Regardless of the specific details in every classification, the main concern for every medical oncologist and pancreatic surgeon is to distinguish between patients who would benefit from the surgical intervention and those who would better receive alternative palliative treatment 
Table 1 Pathological classification of pancreatic cancer

\begin{tabular}{|c|c|c|c|c|c|c|c|}
\hline \multicolumn{7}{|l|}{ M0 } & M1 \\
\hline \multirow[t]{4}{*}{$\mathrm{M} 0$} & & Tis & T1 & $\mathrm{T} 2$ & T3 & T4 & \multirow{4}{*}{$\begin{array}{l}\text { Stage } \\
\text { IV }\end{array}$} \\
\hline & No & $\begin{array}{l}\text { Stage } \\
0\end{array}$ & $\begin{array}{l}\text { Stage } \\
\text { IA }\end{array}$ & $\begin{array}{l}\text { Stage } \\
\text { IB }\end{array}$ & $\begin{array}{l}\text { Stage } \\
\text { IIA }\end{array}$ & \multirow[t]{3}{*}{$\begin{array}{l}\text { Stage } \\
\text { III }\end{array}$} & \\
\hline & N1 & & \multicolumn{3}{|c|}{ Stage IIB } & & \\
\hline & $\mathrm{N} 2$ & & \multicolumn{3}{|c|}{ Stage III } & & \\
\hline M1 & \multicolumn{7}{|c|}{ Stage IV } \\
\hline
\end{tabular}

Abbreviations: M0, no distant metastases; M1, distant organ metastasis; N0, no nodal metastases; N1, 1-3 regional nodal metastases; N2, $\geq 4$ nodal metastases; Tis, carcinoma in situ; $\mathrm{T} 1$, tumor $\leq 2 \mathrm{~cm}$; T2, tumor $>2, \leq 4 \mathrm{~cm}$; T3, tumor $>4 \mathrm{~cm}$; T4, tumor involving celiac axis, CHA or SMA.

options. Radiological assessment plays a crucial role in the detection of the primary tumor, vascular involvement and variants, metastasis, prediction of resectability, and monitoring treatment response. ${ }^{13} \mathrm{High}$-resolution multidetector computed tomography (HR MDCT) is the primary imaging modality of choice for diagnosing and staging pancreatic cancers. Nevertheless, integration of ultrasound (US), computed tomography (CT), and magnetic resonance imaging (MRI) may be the mainstay for accurate determination of tumor extent for optimal management. ${ }^{14-16}$ Herein, we aim to provide a radiological review for "what the surgeon wants to know about pancreatic cancer?"

\section{Pathological Classification}

Pancreatic tumors constitute a heterogeneous group of malignant and benign neoplasms (-Table 2). Majority $(\sim 95 \%)$ occur from the exocrine cells and may arise from the ductal epithelium, acinar cells, or connective tissue. ${ }^{17}$ Pancreatic exocrine tumors include primary adenocarcinoma, cystic neoplasms, solid pseudopapillary tumor, pancreatoblastoma, lymphoma, and other rare tumors. ${ }^{18}$ Pancreatic cystic neoplasms account for about 10-15\% of cystic pancreatic lesions and include most commonly intraductal papillary mucinous neoplasm (IPMN), serous cystadenoma, and mucinous cystic neoplasms ([MCNs] either cystadenoma or cystadenocarcinoma). ${ }^{19}$ Most of the exocrine pancreatic tumors are malignant (only $2 \%$ benign). The endocrine tumors (also called neuroendocrine tumors [NETs]) account for approximately 3 to $4 \%$ of the tumors and are the second most common type. Pancreatic NETs are mostly benign and include insulinoma, gastrinoma, glucagonoma, somatostatinoma, vasoactive intestinal peptide tumor (VIPoma), pancreatic polypeptide-secreting tumors, and nonfunctioning tumors. ${ }^{20}$ Overall, the most common pancreatic malignancy is the pancreatic ductal adenocarcinoma (PDA), which accounts for approximately 85 to $96 \%$ of all pancreatic solid cancers. Some pancreatic cystic neoplasms including some IPMN and some MCNs (either cystadenoma or cystadenocarcinoma), as well as some NETs may be malignant. ${ }^{19,20}$
Table 2 Pathological classification of pancreatic cancer

\begin{tabular}{|l|l|}
\hline \multicolumn{2}{|c|}{ Malignant } \\
\hline Ductal origin & $\begin{array}{l}\text { PDAC } \\
\text { Adenosquamous carcinoma } \\
\text { Osteoclastic giant cell } \\
\text { carcinoma } \\
\text { Colloid carcinoma } \\
\text { Medullary carcinoma } \\
\text { Malignant IPMNs } \\
\text { Malignant MCNs }\end{array}$ \\
\hline Nonductal origin & $\begin{array}{l}\text { Acinar cell carcinoma } \\
\text { Malignant PNETs } \\
\text { Pancreatoblastoma } \\
\text { Solid pseudopapillary } \\
\text { neoplasm } \\
\text { Lymphoma }\end{array}$ \\
\hline Secondary metastasis & \\
\hline \multicolumn{2}{|l|}{ Benign } \\
\hline Serous cystadenoma \\
\hline IPMNs
\end{tabular}

Abbreviations: IPMN, intraductal papillary mucinous neoplasm; MCN, mucinous cystic neoplasm; PDAC, pancreatic ductal adenocarcinoma; PNET, primitive neuroectodermal tumor.

\section{Clinical Presentation}

Presenting symptoms of pancreatic cancer result from a mass effect based on location. Approximately, more than two-thirds (60-70\%) of pancreatic cancers arise in the pancreatic head, with symptoms related to obstruction of the biliary tree and gastroduodenal tract, for example, abdominal pain, jaundice, pruritus, dark urine, and clay-colored stools. Nonspecific symptoms occur with cancers in the pancreatic body or tail (20-25\%), including unexplained weight loss, anorexia, early satiety, dyspepsia, nausea, and depression..$^{21,22}$ In addition, sudden onset of atypical diabetes mellitus in a thin patient older than 50 years is a suggestive criterion needing work-up to rule out pancreatic cancer. ${ }^{23}$ In majority of the cases, these are symptoms of late presentation when curative measures are less likely to have a good effect.

\section{Tumor Markers}

Although discovered around 40 years ago, carbohydrate antigen (CA) 19-9 remains the gold standard serum marker for patients with pancreatic cancer and is still the only tumor marker approved by the U.S. Food and Drug Administration. However, it can also be elevated in other medical conditions such as acute cholangitis, liver cirrhosis, pancreatitis, and obstructive jaundice. Similarly, other tumor markers such as carcinoembryonic antigen and other CAs such as CA50, CA195, CA72-4, and CA125 also have limited accuracy. Therefore, in terms of diagnosis, these are considered poor biomarkers for early pancreatic cancer 
detection. On the other hand, CA 19-9 serum levels can provide valuable information concerning prognosis, overall survival, and treatment response, and predict postoperative recurrence. Recent studies have developed a large number of promising biomarkers including serum proteins and microRNAs, as well as genetic markers that might revolutionize the management approach for pancreatic cancer in future. ${ }^{24}$

\section{Imaging Modalities}

While biopsy is needed to confirm the cancer diagnosis, cross-sectional imaging is essential to detect and narrow the differential diagnosis of a pancreatic mass. ${ }^{25}$

High-Resolution Multidetector Computed Tomography Contrast-enhanced HR MDCT is the most validated imaging modality for the diagnosis and staging of pancreatic cancer. ${ }^{14,15,26,27}$ For optimal detection and staging, using an injection rate of 3 to $4 \mathrm{~mL} / \mathrm{second}$ of $350 \mathrm{mg} / \mathrm{mL}$ of iodinated contrast, the scan is performed during three phases: arterial phase, which occurs around 20 to 25 seconds postinjection, pancreatic (early portal) phase, which occurs at 35 to 40 seconds, and late venous phase, which occurs at 70 seconds. The main goal is to increase tumor visualization by maximizing enhancement difference from the surrounding parenchyma during the arterial phase and to detect the hepatic metastasis during peak hepatic enhancement in the portal venous phase in addition to an assessment of the vascular invasion through the best possible opacification of peripancreatic vessels. ${ }^{26,28}$ Depending on the tumor size, sensitivity of CT for tumor detection is approximately 89 to $97 \%$ for large tumors ${ }^{26}$ and around $77 \%$ for masses $<2 \mathrm{~cm} .{ }^{29}$

PDA usually enhances poorly compared with the surrounding pancreas, appears as a hypoattenuating area ( - Fig. $\mathbf{1})$ in the early phase of dynamic $\mathrm{CT}$, and gradually enhances more on delayed images. However, sometimes this may be isoattenuating or isoenhancing compared with the normal parenchyma and may be difficult to detect. In such cases, secondary signs such as distal pancreatic atrophy and pancreatic ductal dilatation point to the presence of pancreatic mass ( - Fig. 2).

Granata et al discussed the importance of the parenchymal pancreatic phase using the dual-energy MDCT and the perfusion $\mathrm{CT}$ in visualizing the undetected tumors due to lack of attenuation gradient between the tumor and the surrounding parenchyma. ${ }^{30} \mathrm{CT}$ images can be viewed at multiple energy levels on dual-energy $\mathrm{CT}$, which also allows the generation of iodine images and virtual noncontrast (water only) CT images. Iodine images increase lesion conspicuity, improve pancreatic

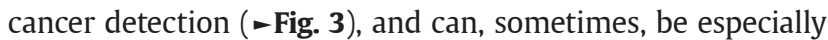
useful in the detection of small and isoattenuating cancers. Low energy or iodine datasets can also be used to create CT angiogram images to improve the staging of pancreatic cancer. Moreover, adding the multiplanar reconstructed images in coronal and sagittal views to the axial images in these novel CT techniques increases the sensitivity for tumor detection and evaluation of local extension. ${ }^{31}$

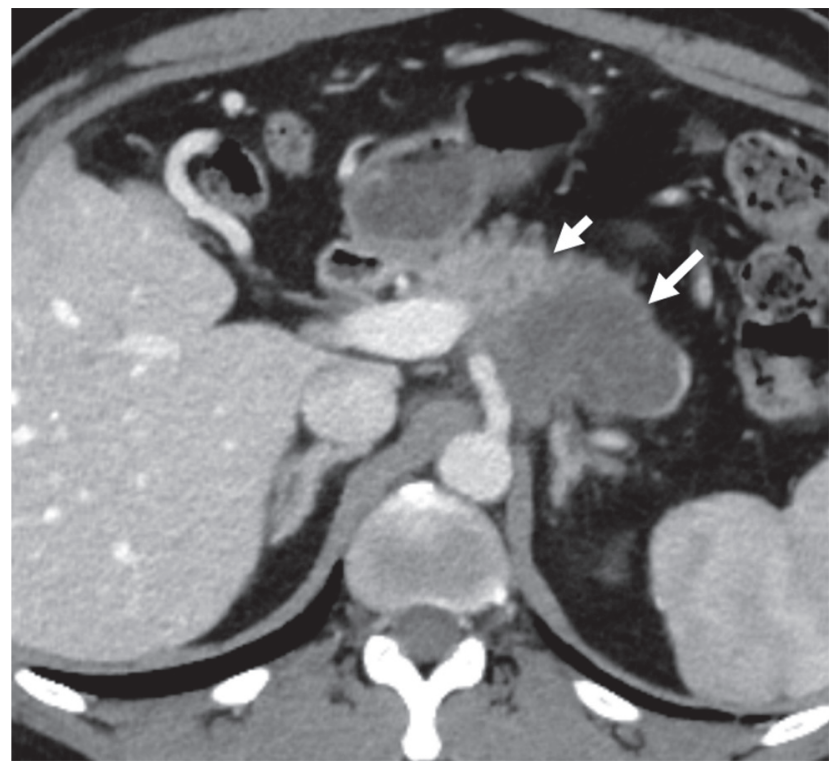

Fig. 1 A 43-year-old male with worsening left flank pain. Axial contrastenhanced computed tomography shows a hypoenhancing mass (arrow) in the pancreatic tail compared with the adjacent enhancing pancreatic parenchyma (short arrow). This was proven to be pancreatic adenocarcinoma.

MRI may be used as a problem-solving tool and to detect the isoattenuating pancreatic masses not seen on CT (-Fig. 4). ${ }^{32,33}$

\section{Magnetic Resonance Imaging}

MRI is very useful in the detection and staging of pancreatic cancers, particularly when CT findings are equivocal. ${ }^{34}$ It has particularly superior diagnostic value for pancreatic cystic lesions and may be more accurate in detecting small hepatic lesions and metastases..$^{35}$ However, there is no significant diagnostic advantage of MRI over contrast-enhanced CT (CECT) (sensitivity of $86 \%$ on CT vs. $84 \%$ on MRI), and combining the two tests does not give more advantage when compared with one test alone. ${ }^{36-38}$ Typically, the most used MRI protocol is pre- and postgadolinium-enhanced T1-weighted images (T1-WI) with and without fat suppression, along with T2-weighted spin-echo sequences. ${ }^{37}$

Pancreatic cancer is hypointense on gadolinium-enhanced $\mathrm{T} 1-\mathrm{WI}$ in the pancreatic and venous phases because it is hypovascular compared with the normal pancreas, and it may become isointense on delayed images due to slow contrast wash-in. ${ }^{39}$ Double duct sign with a dilated common bile duct and pancreatic duct with an abrupt cutoff is classically seen on MR cholangiopancreatography (MRCP) due to pancreatic head masses (-Fig. 5).

The choice between MRI and CT depends on the institutional resources, availability of expertise, and clinician's preference. MRI can also be used in patients with allergy to iodinated contrasts and impaired renal function, whereas MRI may be contraindicated in patients with active pacemakers or in case of incompatible metal or implants in the body. . $3737-39^{\circ}$

In addition, diffusion-weighted imaging (DWI) offers functional tissue evaluation by mapping the restriction of 


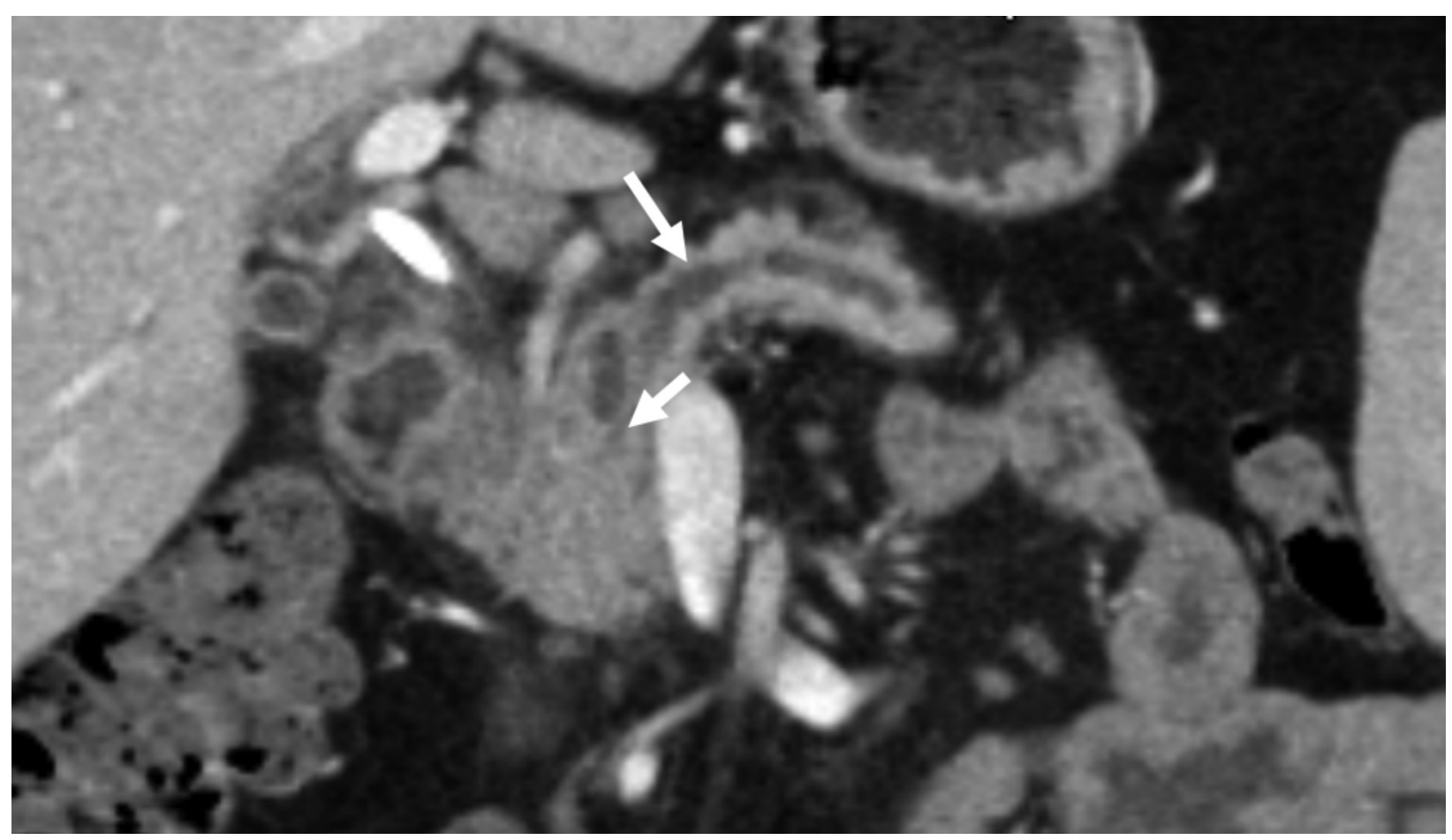

Fig. 2 A 45-year-old male with biliary stent placement for obstructive jaundice. Coronal contrast-enhanced computed tomography shows mild atrophy of the pancreatic body and tail, with underlying dilatation of the pancreatic duct (arrow), which shows an abrupt cutoff in the region of the bulky pancreatic head (short arrow) suspicious for an isoattenuating or isoenhancing mass. Endoscopic ultrasound-guided fine needle aspiration (not shown) revealed pancreatic adenocarcinoma involving the head.

Brownian water molecule motion. Tumors usually show an increase in diffusion restriction as a marker of cellularity and pathologic characteristics of cellular barriers. Calculating and mapping of the apparent diffusion coefficient (ADC) allows for a quantitative assessment of restrictive diffusion. DWI with ADC maps are now been widely studied to estimate the tumor response with encouraging results. ${ }^{40}$

\section{Endoscopic Ultrasound-Guided Fine Needle Aspiration}

Endoscopic ultrasound (EUS) and fine needle aspiration (FNA) may be used in the preoperative assessment of pancreatic cancers and to detect lesions not seen on MDCT and MRI in suspected cases. ${ }^{41}$ The sensitivity of EUS-FNA in diagnosing pancreatic cancer is 80 to $95 \%{ }^{42-44}$; however, its diagnostic accuracy may be lower in cases of obstructive jaundice and chronic pancreatitis. ${ }^{45}$ An absence of a visualized mass lesion on EUS almost certainly rules out pancreatic cancer ${ }^{46}$ Sometimes, EUS may be planned preoperatively to assess tumor resectability, as it accurately visualizes portal vein, splenic vein, and peripancreatic lymph nodes invasion. However, involvement of the superior mesenteric artery and the superior mesenteric vein can be better visualized by MDCT. ${ }^{43,44,47,48}$ The main limitations of EUS is its high dependence on operator experience and the limited availability of skilled experts. ${ }^{34}$

\section{Positron Emission Tomography and Positron Emission Tomography-Computed Tomography}

Positron emission tomography (PET)-CT utilizes the combined functional assessment of PET with anatomical aspect and spatial resolution of CT. However, the superiority of this technique over MDCT in detecting pancreatic cancers is still a controversial issue, as some studies have proven a higher value of PET-CT over MDCT ${ }^{49,50}$ and some studies have shown no equivalent results. ${ }^{51}$ PET-CT is inferior to CT in evaluating regional lymph nodes and vascular involvement, but it is superior to CT in detecting distant metastases ( -Fig. 6). ${ }^{49,52}$ Focused research may be needed to evaluate the role of PET-CT for the diagnosis and staging of pancreatic cancer, particularly in patients with a negative or indeterminate MDCT.

\section{Staging and Assessment of Resectability}

The TNM staging system is the most commonly used staging method to assess the tumor status (T), lymph nodes $(\mathrm{N})$, and metastasis $(\mathrm{M})^{53}$ (-Table 2 ). The most desired result of staging is to segregate the resectable, borderline resectable, locally advanced, and metastatic tumors. Stages I and II are evidently resectable (-Figs. 3-5). Stage IV is defined by distant metastasis ( - Fig. 6); consequently, these will not benefit from resection and are directed to palliative treatment. Stage III tumor gets more targeted attention from the surgeons and radiologists, as they are localized tumors with major vessel involvement and need subcategorization into locally advanced unresectable tumors ( - Fig. 7) and borderline resectable tumors ( - Fig. 8). Furthermore, the borderline resectable pancreatic cancer may benefit from resection, especially if preceded by neoadjuvant treatment. ${ }^{54}$ 

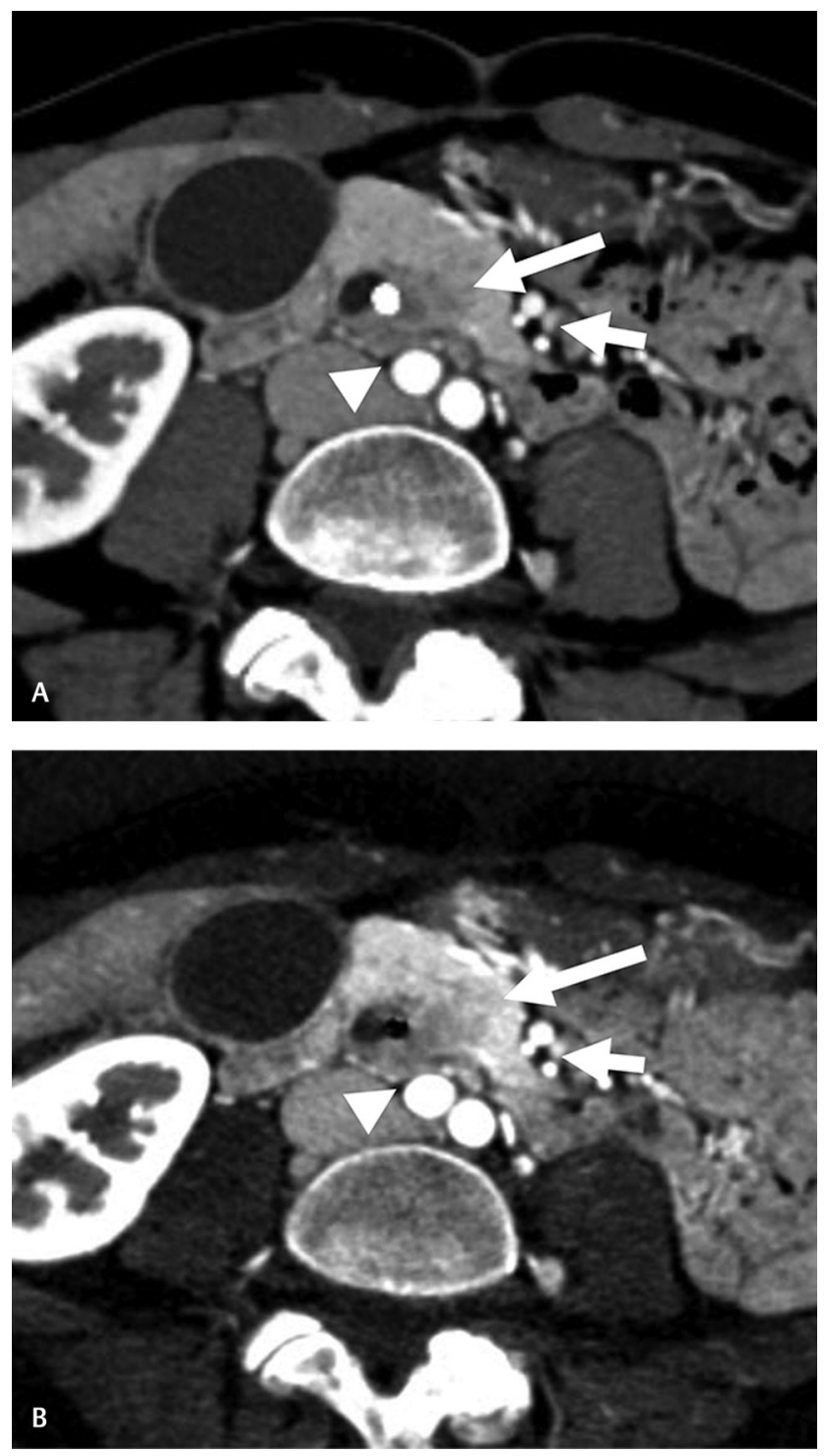

Fig. 3 A 49-year-old female presented with abdominal pain, nausea, and jaundice. Axial images of the pancreatic postcontrast phase of (A) dual-energy computed tomography (DECT) shows a vague hypodense pancreatic head mass (long arrows), which is better seen and more conspicuous on the (B) iodine map images of the DECT. The superior mesenteric artery and vein (short arrows) as well the adjacent aortic bifurcation (arrowheads) were separate from the mass, with clear fat planes suggestive of a resectable tumor. This was proven to be periampullary pancreatic adenocarcinoma following Whipple surgery.

Despite the multiplestaging systems and consensus meetings, there is no agreement on the exact criteria of tumor resectability. The MD Anderson Cancer Center (MDACC) and the National Comprehensive Cancer Network established the two most commonly used definitions for local staging to categorize borderline resectable cancers. ${ }^{7.8}$ - Table 3 presents a comparison of the two most commonly cited definitions of borderline resectable pancreatic cancers. - Table $4^{55}$ shows the imaging criteria adopted by the AHPBA/SSO/SSAT (Americas Hepato-Pancreato-Biliary Association/Society of Surgical Oncology/Society for Surgery of the Alimentary Tract) versus the MDACC criteria ${ }^{8,27,56}$ for potentially resectable, borderline resectable, and locally advanced/ unresectable pancreatic cancers.
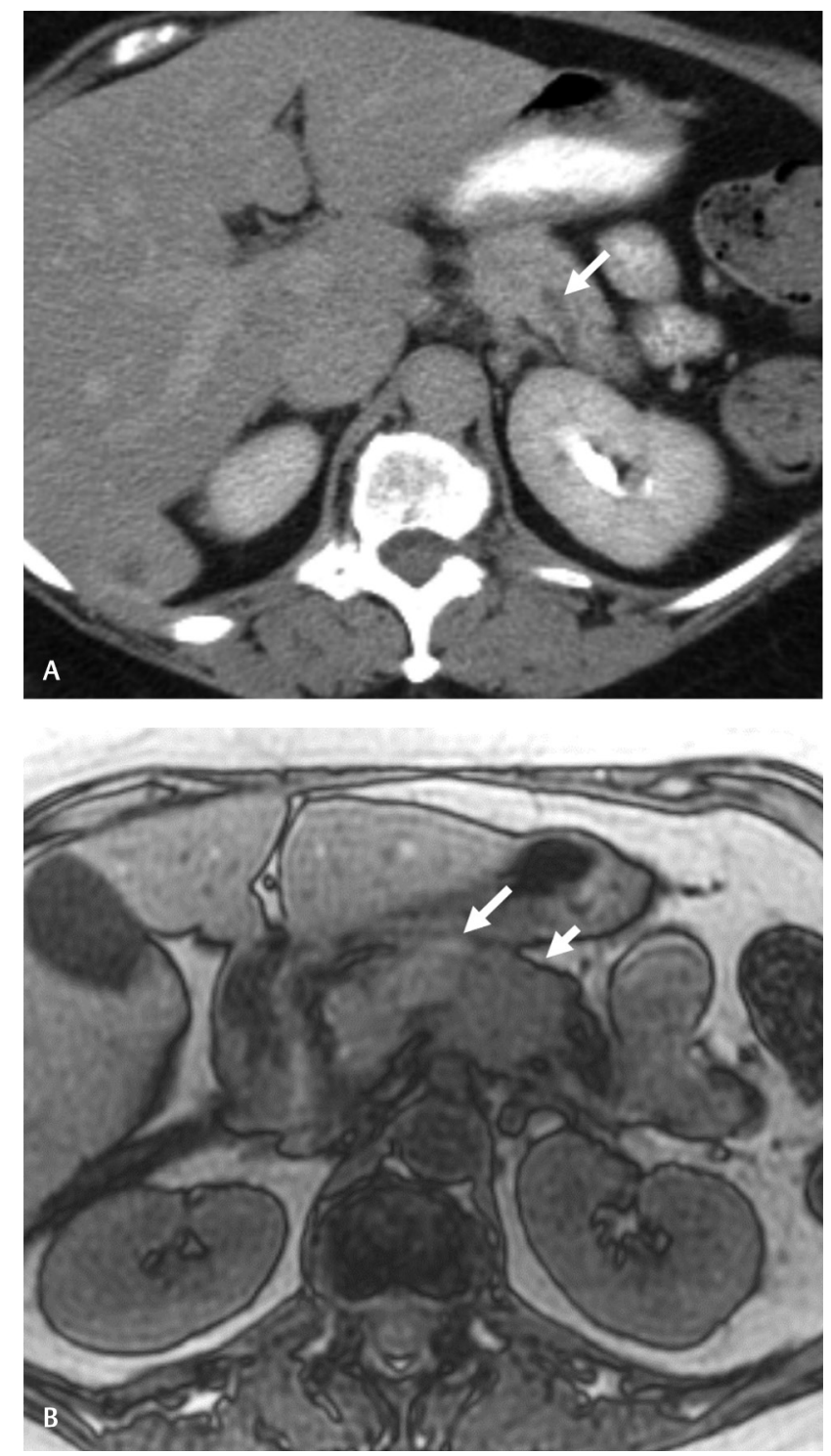

Fig. 4 A 63-year-old male presented with weight loss and pulmonary metastases. (A) Axial contrast-enhanced computed tomography revealed mild dilatation of the pancreatic duct (arrow) in the tail, with an abrupt cutoff in the region of the pancreatic body. No obvious pancreatic mass was seen on CT. As the isoattenuating mass was suspected, magnetic resonance imaging (MRI) was performed, which clearly shows a hypointense potentially resectable mass (short arrow) in the pancreatic body compared with a normal hyperintense signal of the adjacent pancreatic parenchyma (long arrow) on T1-weighted image (B), with no involvement of the adjacent vasculature.

\section{Preoperative Planning Based on Imaging}

Tumor location, pathology, and relation to adjacent structures (e.g., pancreatic duct and vascular supply) are the main determining factors for the choice of the surgical technique. The main goal of the treatment is to achieve a negative margin status ( $\mathrm{R} 0$ resection). ${ }^{57}$ The main two surgeries for PDA are pancreaticoduodenectomy (PD) $)^{58}$ and distal pancreatectomy (DP) with splenectomy. PD (Whipple procedure) is a major surgery performed for the pancreatic head and neck cancers and involves en bloc resection of the pancreatic head with the uncinate process, distal stomach, duodenum, proximal jejunum, gallbladder, distal common bile duct, and regional lymphadenectomy. ${ }^{59}$ 

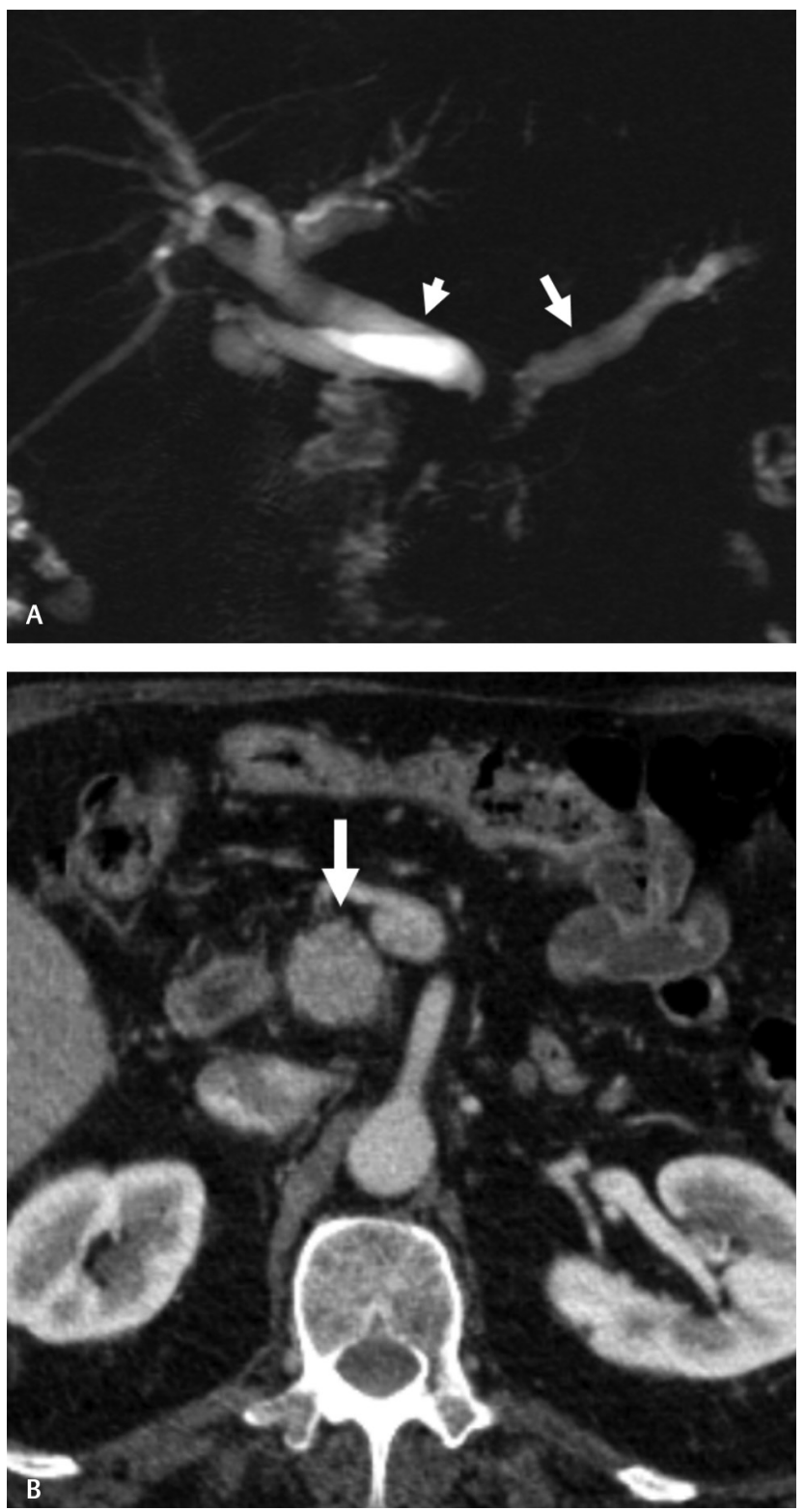

Fig. 5 A 60-year-old female presented with pancreatic head cancer, who underwent pancreaticoduodenectomy (Whipple surgery). (A) Presurgical magnetic resonance cholangiopancreatography shows dilated common bile duct (short arrow) and the main pancreatic duct (long arrow), with classic double duct sign and an abrupt cutoff in the region of the pancreatic head. This was because of the pancreatic adenocarcinoma that corresponded to the locally confined isoenhancing mass in the pancreatic head (arrow) seen on contrast-enhanced computed tomography (CT) (B) with no involvement of the adjacent vasculature and hence a resectable tumor.

DP is performed for distal pancreatic cancers through open procedure or by laparoscopy, depending on the location, size, and involvement of the surroundings. En bloc splenectomy is usually performed in cases of distal pancreatic cancer to achieve the targeted R0. ${ }^{60,61}$ These procedures and the potential postsurgical complications are described in detail elsewhere in this issue.

\section{Role of Neoadjuvant Therapy}

Patients with a borderline resectable tumor should receive neoadjuvant chemotherapy or combined chemoradiotherapy to categorize it as a resectable (downstage) tumor, which will benefit from surgery, or an unresectable tumor, which will receive palliative chemotherapy. ${ }^{62}$ Neoadjuvant therapies such as FOLFIRINOX (folinic acid, fluorouracil, irinotecan, oxaliplatin combination) and gemcitabine-based regimens have shown promising results in the downstaging of pancreatic cancers, ${ }^{62-64}$ and further improved therapies and clinical trials are needed. It is important to mention that the response (downstaging) of borderline resectable pancreatic cancer by neoadjuvant therapy may not be reflected on imaging using the Response Evaluation Criteria in Solid Tumors (RECIST) or modified RECIST (RECIST 1.1), 55 as these are conventional anatomical imaging-based criteria and have limitations in metabolic assessment. The fluorine- 18 fluorodeoxyglucose PET-based criteria (PERCIST [PET response criteria in solid tumors]) seem to be more valuable in such cases. In a recent study, Dalah et al compared both RECIST 1.1 and PERCIST 1.0 criteria to assess the tumor treatment response and found that PERCIST may increase the chance to detect treatment response and is more informative due to its ability to assess tumor viability compared with RECIST 1.1 criteria. $^{65}$

\section{Malignant Cystic Neoplasia of the Pancreas}

IPMNs and MCNs are the main cystic pancreatic lesions, which are found to be precursor lesions with premalignant potential in adenocarcinoma sequences. ${ }^{66}$

\section{Malignant Intraductal Papillary Mucinous Neoplasms}

Majority of the IPMNs involve the pancreatic ductal side branches, but they may also affect the main pancreatic duct (MPD) or both. IPNMs of the ductal side branches show less aggressive behavior as compared with those involving the main duct as the prevalence of invasive cancer is higher in the main duct IPMN (23-57\%) the tumor is crucial for the prognosis ( - Fig. 9). ${ }^{66}$ IPMNs are subdivided into four types-gastric, intestinal, pancreatobiliary, and oncocytic-based on the histopathological features ${ }^{69}$; the pancreatobiliary subtype has the highest malignant potential among the first three, whereas the prognosis of the oncocytic subtype is not yet well studied compared with the other IPMNs. ${ }^{70}$ Branch duct (BD) IPMNs have less malignant potential than MPD and combined-type IPMNs, with a prevalence of 6 to $46 \%$ for invasive carcinoma, ${ }^{67,71,72}$ and they usually occur in the uncinate process as a small cyst. When the IPMN involves both the side branches and MPD, it is classified as a combined-type IPMN. It is diagnosed by visualizing the dilatation of the MPD and the side branches in the setting of IPMN. ${ }^{73}$

Staging of all malignant IPMNs is similar to that of PDA. However, imaging features and management differ slightly from that of PDA. MRI has more value than MDCT because 

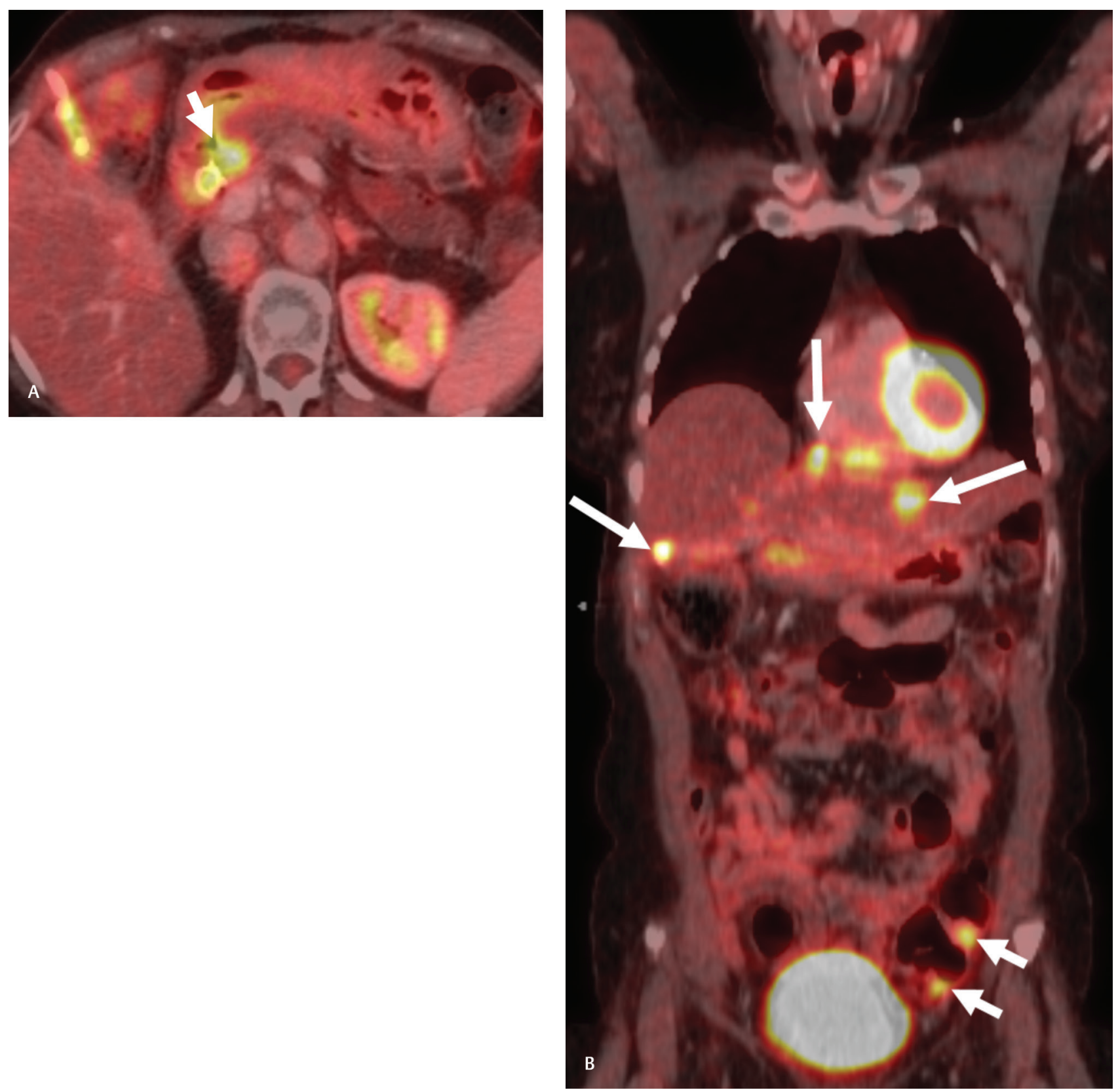

Fig. 6 A 58-year-old female presented with stage IV metastatic pancreatic head cancer on chemotherapy, with a recurrent elevation of CA (carbohydrate antigen) 19-9 following earlier treatment response. (A) Axial fused color fluorine-18 fluorodeoxyglucose positron emission tomography-computed tomography (PET-CT) image shows a hypermetabolic mass in the pancreatic head (arrow) consistent with viable pancreatic cancer. (B) Coronal fused PET-CT image shows multiple hypermetabolic hepatic metastases (long arrows). It also revealed new hypermetabolic nodules along the periserosal aspect of the sigmoid colon consistent with peritoneal metastases (short arrows), which were not seen on contrast-enhanced CT (not shown).

of its ability to detect ductal communication, and that is why MRCP is considered more accurate for the diagnosis of IPMNs. ${ }^{74}$ The main features that suggest malignancy on imaging include MPD dilatation of more than $1.5 \mathrm{~cm}$ in diameter, the presence of enhancing mural nodules or focal hypoenhancing soft tissue mass, and bile duct obstruction. ${ }^{75}$ All MPD lesions are managed by resection because of their high malignant potential. ${ }^{67}$ The main imaging feature in BD IMPNs is the dilatation of the side ductal branches with the communication to the MPD. Enhancing soft tissue nodularity within it suggests malignancy, and tumors $>3 \mathrm{~cm}$ in size have a higher risk of malignancy. ${ }^{76}$ If the patient has an asymptomatic BD IPMN without any suggestive features of malignancy, conservative treatment and follow-up are the best approaches to adopt. ${ }^{77}$

\section{Malignant Mucinous Cystic Neoplasms}

This usually occurs in the pancreatic body and tail. Patients usually present with vague abdominal pain and discomfort, with classic symptoms of pancreatitis in rare cases. ${ }^{78}$ Staging is similar to that for PDA. It is usually visualized as large $(>6 \mathrm{~cm})$ cystic masses, thick septae, and/or enhancing soft tissue ( - Fig. 10). 


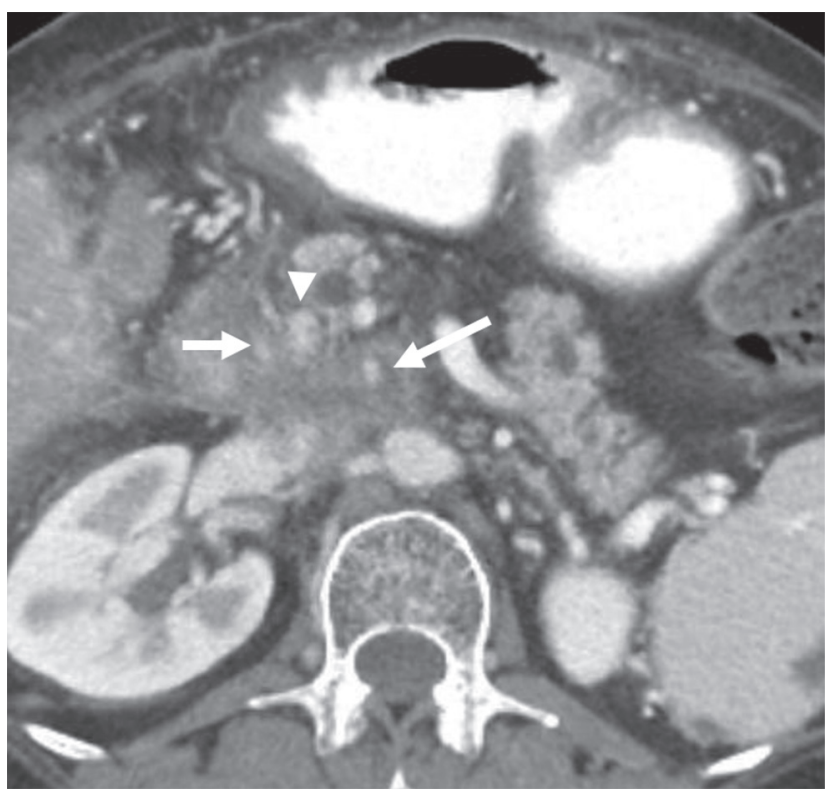

Fig. 7 A 67-year-old female presented with locally advanced pancreatic cancer. Contrast-enhanced computed tomography shows a large irregular hypoenhancing mass involving the pancreatic head and uncinated process. It completely (360-degree circumference) encases the proximal superior mesenteric artery (long arrow) and branch (short arrow) of the superior mesenteric vein but partially (180-degree circumference) encases the superior mesenteric vein (arrowhead).

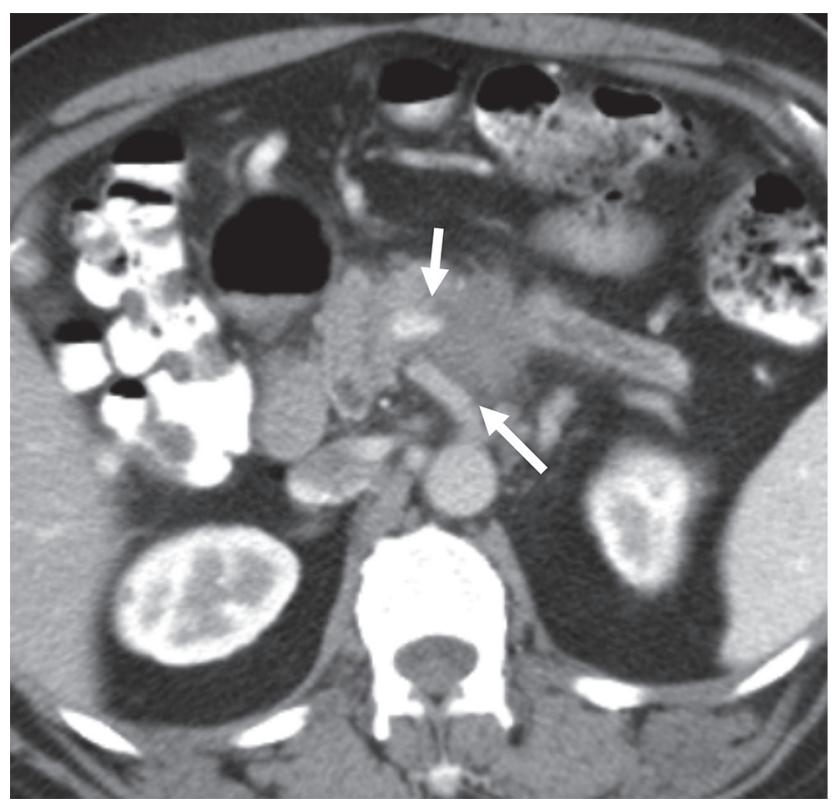

Fig. 8 A 66-year-old male presented with abdominal pain and a weight loss of $15 \mathrm{lb}$. over 1 month. Contrast-enhanced computed tomography revealed a pancreatic body mass extending in the peripancreatic region and focally abutting ( $<180$-degree circumference) the superior mesenteric artery (long arrow) and portomesenteric venous confluence (short arrow) without encasement. This was proven to be pancreatic adenocarcinoma and classified as borderline resectable based on imaging. On neoadjuvant chemotherapy, the tumor decreased in size. Unfortunately, chemotherapy was stopped for a while due to chemotoxicity, and cancer started growing again. The patient subsequently developed liver metastases, which were deemed unresectable.
Because radiological distinction between benign and malignant lesions is often difficult, all mucinous lesions are managed as premalignant and surgically resected. ${ }^{79}$

\section{Malignant Pancreatic Neuroendocrine Neoplasia}

Gastroenteropancreatic NETs, also called carcinoids, can be nonfunctional (NF-PNETs) or functional (F-PNETs). In practice, they are also known as nonsyndromic PNETs or syndromic PNETs, with the latter being named according to the predominant hormone secreted by the tumor, for example, insulinomas, gastrinomas, VIPomas, glucagonomas, and so on.$^{80}$ Most of PNETs are benign. The malignant PNETs represent around $1.3 \%$ of pancreatic malignancies, and the incidence is growing because of the advancements in imaging techniques that lead to increased detection. ${ }^{81}$ Although extremely rare in children, they can occur at any adult age, with equal gender frequency. Per the World Health Organization classification, PNETs are classified as grade 1 or grade 2 or as neuroendocrine carcinoma based on the mitotic count and K1-67 index. Morphological or imaging criteria of malignancy include metastases to the regional lymph nodes, invasion of adjacent organs, and size more than $2 \mathrm{~cm} .{ }^{82}$ Preoperative imaging is important in the management and prediction of prognosis. Research linking malignant potential of these tumors using morphological criteria with MDCT and MRI modalities is underway. ${ }^{83,84}$ Per one of the pathological classifications, nonsimple nodular PNET is more associated with morphologic features and malignant potential than simple nodular type. ${ }^{85}$

\section{Imaging and Management}

MDCT plays the main role in evaluating PNETs, with a diagnostic sensitivity of $>80 \%$ (-Fig. 11). Most F-PNETs are less than $3 \mathrm{~cm}$ in size, hyperenhancing, and therefore better seen in the portal venous or pancreatic phase. Syndromic PNETs can be homogeneous, heterogeneous, or cystic in appearance. Cystic degeneration, calcification, and necrosis are more common in NF-PNETs, which are commonly larger than F-PNETs. ${ }^{86}$

MRI is preferred in patients with allergy to iodinated contrast and renal impairment and has the advantage of lack of radiation compared with CT. Furthermore, MRI is superior to $\mathrm{CT}$ in detecting smaller pancreatic lesions and liver metastases. ${ }^{87}$ Sensitivity and specificity of MRI in detecting small islets cell tumors are around $85 \%{ }^{88}$ Other helpful imaging techniques for evaluation of PNETs include EUS, OctreoScan, and other functional imaging such as somatostatin receptor imaging and PET scan labeled with somatostatin analogues. Gallium-68 DOTA-TATE PET-CT scan, which shows the highest affinity for somatostatin receptor 2 tissues, is found to have higher accuracy and detection rate..$^{89,90}$

Based on the location, resectable lesions in the pancreatic tail can be treated with DP, whereas lesions in the head require Whipple surgery. Patients with oligometastatic disease in the liver may benefit from surgical resection 
Table 3 Definition of borderline resectable pancreatic cancer according to both MDACC and NCCN criteria

\begin{tabular}{|c|c|c|}
\hline & MDACC & NCCN \\
\hline Arterial & $\begin{array}{l}\text { SMA } \\
\text { - Tumor abutment } \leq 180 \text { degrees (one half or } \\
\text { less) of the circumference of the artery; peri- } \\
\text { arterial stranding and tumor points of contact } \\
\text { forming a convexity against the vessel improve } \\
\text { chances of resection } \\
\text { CA/CHA } \\
\text { - Short-segment encasement/abutment of the } \\
\text { CHA (typically at the gastroduodenal origin); } \\
\text { the surgeon should be prepared for vascular } \\
\text { resection/interposition grafting }\end{array}$ & $\begin{array}{l}\text { Pancreatic head/uncinate process } \\
\text { - Tumor adjacent to CHA, not passing into CA and CHA branch, } \\
\text { conditions for safe and radical resection with reconstruction } \\
\text { - Tumor adhering to the SMA at } \leq 180 \text { degrees of its } \\
\text { circumference } \\
\text { - The presence of a vascular anatomical variant in the arterial } \\
\text { system (e.g., an additional right HA) and its position rela- } \\
\text { tive to the tumor and/or infiltration by the tumor should } \\
\text { be taken into account during the planning of the surgical } \\
\text { technique } \\
\text { Body/tail } \\
\text { - Adherence of the tumor to CA at } \leq 180 \text { degrees of its } \\
\text { circumference } \\
\text { - Adherence of the tumor to the CA at }>180 \text { degrees of its } \\
\text { circumference without the features of pulling the wall of } \\
\text { this vessel into the tumor, provided that the lesion is not } \\
\text { in contact with the aorta or the gastroduodenal artery } \\
\text { (some experts believe that this criterion qualifies the case } \\
\text { as inoperative) }\end{array}$ \\
\hline Venous & $\begin{array}{l}\text { SMV/PV } \\
\text { - Short-segment occlusion with suitable vessel } \\
\text { above and below; segmental venous occlusion } \\
\text { alone without SMA involvement is rare and } \\
\text { should be apparent on CT images }\end{array}$ & $\begin{array}{l}\text { - Tumor adhering to SMV or PV at } \leq 180 \text { degrees of circumfer- } \\
\text { ence, changing the shape of the vessel } \\
\text { - Presence of venous thrombosis with preserved normal ves- } \\
\text { sels on the proximal and distal parts of the infiltration site } \\
\text { conditions for safe and radical venous resection with subse- } \\
\text { quent reconstruction } \\
\text { - The tumor adheres to the IVC }\end{array}$ \\
\hline
\end{tabular}

Abbreviations: CA, celiac axis; CHA, common hepatic artery; CT, computed tomography; HA, hepatic artery; IVC, inferior vena cava; MDACC, MD Anderson Cancer Center; NCCN, National Comprehensive Cancer Network; PV, portal vein; SMA, superior mesenteric artery; SMV, superior mesenteric vein.

Table 4 AHPBA/SSO/SSAT and MDACC classifications of localized pancreatic cancer

\begin{tabular}{|c|c|c|c|c|c|c|}
\hline & \multicolumn{3}{|c|}{ AHPBA/SSO/SSAT classification ${ }^{27}$} & \multicolumn{3}{|c|}{ MDACC classification $^{8,56}$} \\
\hline Localization & $\begin{array}{l}\text { Potentially } \\
\text { resectable }\end{array}$ & $\begin{array}{l}\text { Borderline } \\
\text { resectable }\end{array}$ & $\begin{array}{l}\text { Locally } \\
\text { advanced }\end{array}$ & $\begin{array}{l}\text { Potentially } \\
\text { resectable }\end{array}$ & $\begin{array}{l}\text { Borderline } \\
\text { resectable }\end{array}$ & Locally advanced \\
\hline SMV/PV & $\begin{array}{l}\text { No abut- } \\
\text { ment }^{\mathrm{a}} \text { or } \\
\text { encasement }\end{array}$ & $\begin{array}{l}\text { Abutment, } \\
\text { encasement, } \\
\text { or occlusion }\end{array}$ & $\begin{array}{l}\text { Not } \\
\text { reconstructible }\end{array}$ & $\begin{array}{l}\text { Abutment or } \\
\text { encasement } \\
\text { without } \\
\text { occlusion }\end{array}$ & $\begin{array}{l}\text { Short-segment } \\
\text { occlusion }\end{array}$ & $\begin{array}{l}\text { Not } \\
\text { reconstructible }\end{array}$ \\
\hline SMA & $\begin{array}{l}\text { No abutment } \\
\text { or encasement }\end{array}$ & Abutment & Encasement & $\begin{array}{l}\text { No abut- } \\
\text { ment or } \\
\text { encasement }\end{array}$ & Abutment & Encasement \\
\hline $\mathrm{CHA}$ & $\begin{array}{l}\text { No abutment } \\
\text { or encasement }\end{array}$ & $\begin{array}{l}\text { Abutment or } \\
\text { short-segment } \\
\text { encasement }\end{array}$ & $\begin{array}{l}\text { Long-segment } \\
\text { encasement }\end{array}$ & $\begin{array}{l}\text { No abut- } \\
\text { ment or } \\
\text { encasement }\end{array}$ & $\begin{array}{l}\text { Abutment or } \\
\text { short-segment } \\
\text { encasement }\end{array}$ & $\begin{array}{l}\text { Long-segment } \\
\text { encasement }\end{array}$ \\
\hline Celiac trunk & $\begin{array}{l}\text { No abutment } \\
\text { or encasement }\end{array}$ & $\begin{array}{l}\text { No abutment } \\
\text { or encasement }\end{array}$ & Abutment & $\begin{array}{l}\text { No abut- } \\
\text { ment or } \\
\text { encasement }\end{array}$ & Abutment & Encasement \\
\hline
\end{tabular}

Abbreviations: AHPBA, Americas Hepato-Pancreato-Biliary Association; CHA, common hepatic artery; MDACC, MD Anderson Cancer Center; PV, portal vein; SMA, superior mesenteric artery; SMV, superior mesenteric vein; SSO, Society of Surgical Oncology; SSAT, Society for Surgery of the Alimentary Tract.

Source: adapted from Katz et al. ${ }^{55}$

aLess than 180 degrees of vascular circumference. ${ }^{b}$ At least 180 degrees of vascular circumference. 


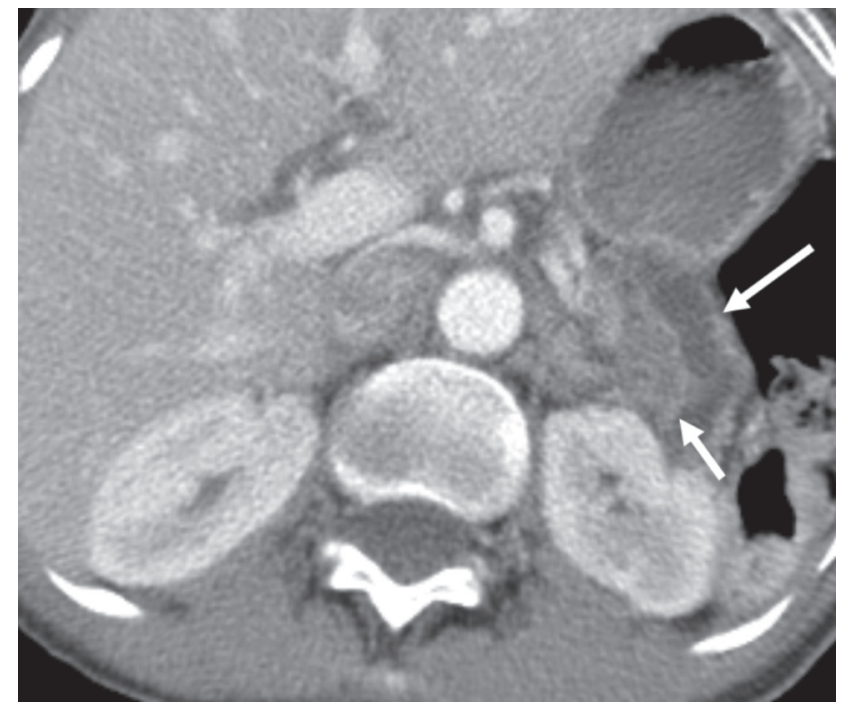

Fig. 9 A 72-year-old female presented with epigastric pain and weight loss. Axial contrast-enhanced computed tomography showed the dilated main pancreatic duct (long arrow) in the tail, with a large heterogeneously enhancing soft tissue component (short arrow) along its posteromedial aspect suspicious for malignant intraductal mucinous neoplasm. Endoscopic ultrasound-guided fine needle aspiration confirmed the diagnosis.

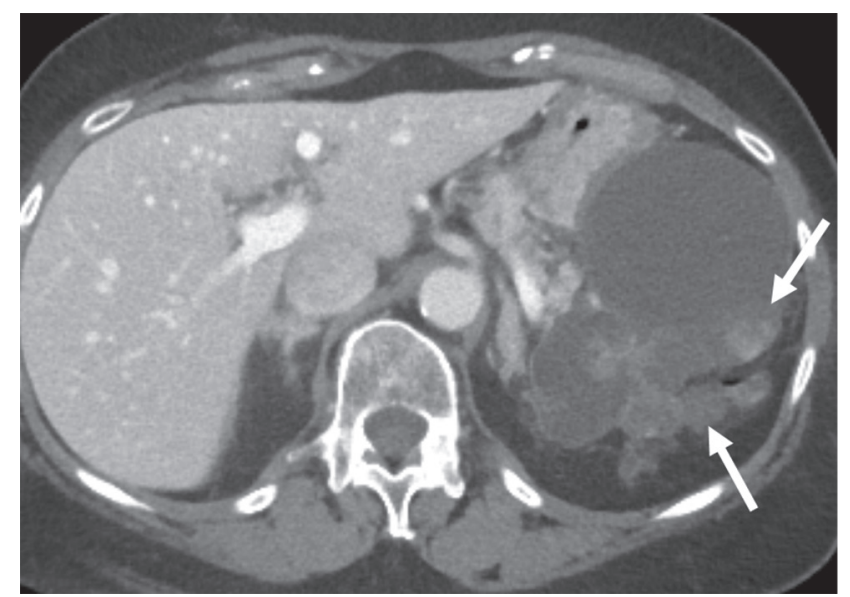

Fig. 10 An 85-year-old female presented with abdominal pain. Axial contrast-enhanced computed tomography showed a complex lobulated cystic mass involving the pancreatic tail, with eccentric solid contents (arrows) suspicious for malignant cystic pancreatic neoplasm. Endoscopic ultrasound-guided fine needle aspiration confirmed the diagnosis of mucinous cystadenocarcinoma. Although distal pancreatectomy was considered in view of the location of the mass, the patient underwent radiotherapy due to comorbidities.

or hepatic artery chemoembolization. Syndromic PNETs cases should undergo endocrinological review to search for other neoplasms depending on the syndrome affecting them, such as multiple endocrine neoplasia-1 (Wermer's syndrome), von Hippel Lindau's disease, neurofibromatosis-1 (von Recklinghausen's disease), and tuberous sclerosis complex..$^{91,92}$

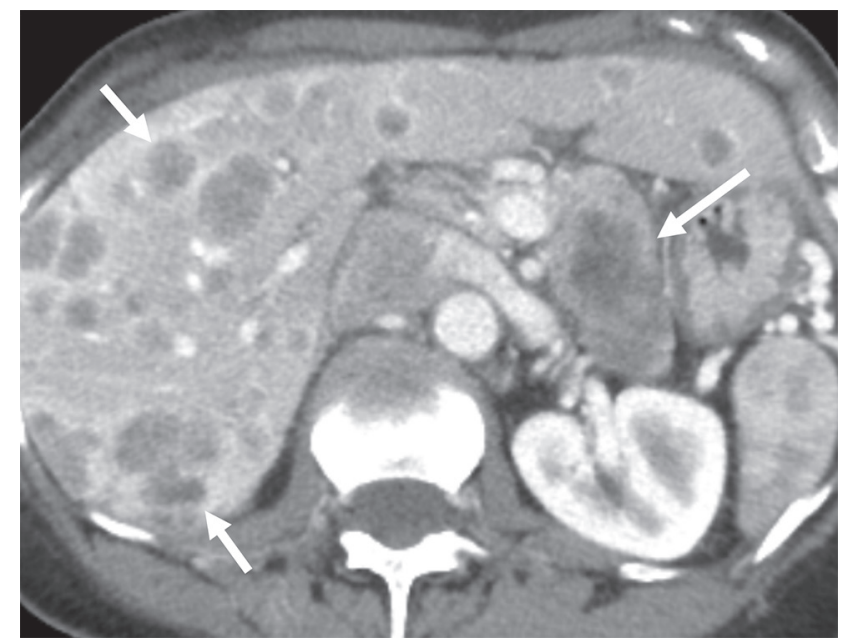

Fig. 11 A 64-year-old female presented with persistent back pain. Axial contrast-enhanced computed tomography showed a large hypoenhancing mass in the pancreatic tail (long arrow), with multiple rim-enhancing liver nodules and masses (small arrows) suspicious for liver metastases. Liver mass biopsy revealed dedifferentiated neuroendocrine cancer. Pancreatic mass was presumed to be the primary neuroendocrine carcinoma.

\section{Conclusion}

Pancreatic cancers constitute a heterogeneous group of neoplasms, including mainly adenocarcinoma, malignant cystic neoplasms, and PNETs. With the recent advances in cancer management, radiologists and surgeons should always be on the same page to provide the best quality of care in these cases. In this review, we highlight the main types of invasive pancreatic cancers and discuss the role of imaging in determining the resectability of pancreatic tumors and the role of neoadjuvant treatment in downstaging borderline or unresectable cases in addition to featuring significant postsurgical complications.

\section{Funding \\ None.}

\section{Conflict of Interest}

None declared.

\section{References}

1 Siegel RL, Miller KD, Jemal A. Cancer statistics, 2019. CA Cancer J Clin 2019;69(1):7-34

2 Malvezzi M, Carioli G, Bertuccio P, et al. European cancer mortality predictions for the year 2017, with focus on lung cancer. Ann Oncol 2017;28(5):1117-1123

3 Clancy TE. Surgery for pancreatic cancer. Hematol Oncol Clin North Am 2015;29(4):701-716

4 De La Cruz MS, Young AP, Ruffin MT. Diagnosis and management of pancreatic cancer. Am Fam Physician 2014;89(8):626-632

5 Jeune F, Coriat R, Prat F, Dousset B, Vaillant JC, Gaujoux S. Pancreatic cancer surgical management. Presse Med 2019;48(3 Pt 2):e147-e158 
6 Hartwig W, Werner J, Jäger D, Debus J, Büchler MW. Improvement of surgical results for pancreatic cancer. Lancet Oncol 2013;14(11):e476-e485

7 Tempero MA, Malafa MP, Al-Hawary M, et al. Pancreatic adenocarcinoma, version 2.2017, NCCN clinical practice guidelines in oncology. J Natl Compr Canc Netw 2017;15(8):1028-1061

8 Varadhachary GR, Tamm EP, Abbruzzese JL, et al. Borderline resectable pancreatic cancer: definitions, management, and role of preoperative therapy. Ann Surg Oncol 2006;13(8):1035-1046

9 Reynolds RB, Folloder J. Clinical management of pancreatic cancer. J Adv Pract Oncol 2014;5(5):356-364

10 Lopez NE, Prendergast C, Lowy AM. Borderline resectable pancreatic cancer: definitions and management. World J Gastroenterol 2014;20(31):10740-10751

11 Zaky AM, Wolfgang CL, Weiss MJ, Javed AA, Fishman EK, Zaheer A. Tumor-vessel relationships in pancreatic ductal adenocarcinoma at multidetector CT: different classification systems and their influence on treatment planning. Radiographics 2017;37(1):93-112

12 Bockhorn M, Uzunoglu FG, Adham M, et al; International Study Group of Pancreatic Surgery. Borderline resectable pancreatic cancer: a consensus statement by the International Study Group of Pancreatic Surgery (ISGPS). Surgery 2014;155(6):977-988

13 Scialpi M, Reginelli A, D’Andrea A, et al. Pancreatic tumors imaging: an update. Int J Surg 2016;28(1, Suppl 1):S142-S155

14 Fenchel S, Boll DT, Fleiter TR, Brambs HJ, Merkle EM. Multislice helical CT of the pancreas and spleen. Eur J Radiol 2003;45(Suppl 1):S59-S72

15 Seo JW, Hwang HK, Lee $M$, et al. Normal postoperative computed tomography findings after a variety of pancreatic surgeries. Korean J Radiol 2017;18(2):299-308

16 Li JH, He R, Li YM, Cao G, Ma QY, Yang WB. Endoscopic ultrasonography for tumor node staging and vascular invasion in pancreatic cancer: a meta-analysis. Dig Surg 2014;31(4-5):297-305

17 Low G, Panu A, Millo N, Leen E. Multimodality imaging of neoplastic and nonneoplastic solid lesions of the pancreas. Radiographics 2011;31(4):993-1015

18 Rishi A, Goggins M, Wood LD, Hruban RH. Pathological and molecular evaluation of pancreatic neoplasms. Semin Oncol 2015;42(1):28-39

19 Dudeja V, Allen PJ. Premalignant cystic neoplasms of the pancreas. Semin Oncol 2015;42(1):70-85

20 Feig BW, Ching CD, The MD Anderson Surgical Oncology Handbook. 6th ed. Philadelphia, PA: Wolters Kluwer Health Adis (ESP); 2018

21 Krech RL, Walsh D. Symptoms of pancreatic cancer. J Pain Symptom Manage 1991;6(6):360-367

22 American gastroenterological association medical position statement: epidemiology, diagnosis, and treatment of pancreatic ductal adenocarcinoma. Gastroenterology 1999;117(6):1463-1484

23 Sah RP, Nagpal SJ, Mukhopadhyay D, Chari ST. New insights into pancreatic cancer-induced paraneoplastic diabetes. Nat Rev Gastroenterol Hepatol 2013;10(7):423-433

24 Loosen SH, Neumann UP, Trautwein C, Roderburg C, Luedde T. Current and future biomarkers for pancreatic adenocarcinoma. Tumour Biol 2017;39(6):1010428317692231

25 Pappas SG, Christians KK, Tolat PP, et al. Staging chest computed tomography and positron emission tomography in patients with pancreatic adenocarcinoma: utility or futility? HPB (Oxford) 2014;16(1):70-74

26 Wong JC, Lu DS. Staging of pancreatic adenocarcinoma by imaging studies. Clin Gastroenterol Hepatol 2008;6(12):1301-1308

27 Callery MP, Chang KJ, Fishman EK. Talamonti MS, William Traverso L, Linehan DC. Pretreatment assessment of resectable and borderline resectable pancreatic cancer: expert consensus statement. Ann Surg Oncol 2009;16(7):1727-1733

28 Tamm EP, Balachandran A, Bhosale PR, et al. Imaging of pancreatic adenocarcinoma: update on staging/resectability. Radiol Clin North Am 2012;50(3):407-428

29 Brennan DD, Zamboni GA, Raptopoulos VD, Kruskal JB. Comprehensive preoperative assessment of pancreatic adenocarcinoma with 64-section volumetric CT. Radiographics 2007;27(6):1653-1666

30 Granata V, Fusco R, Catalano O, et al. Multidetector computer tomography in the pancreatic adenocarcinoma assessment: an update. Infect Agent Cancer 2016;11:57

31 Ichikawa T, Erturk SM, Sou H, et al. MDCT of pancreatic adenocarcinoma: optimal imaging phases and multiplanar reformatted imaging. AJR Am J Roentgenol 2006;187(6):1513-1520

32 Ichikawa T, Haradome H, Hachiya J, et al. Pancreatic ductal adenocarcinoma: preoperative assessment with helical CT versus dynamic MR imaging. Radiology 1997;202(3): 655-662

33 Prokesch RW, Chow LC, Beaulieu CF. Bammer R, Jeffrey RB Jr. Isoattenuating pancreatic adenocarcinoma at multi-detector row CT: secondary signs. Radiology 2002;224(3):764-768

34 Tummala P, Junaidi O, Agarwal B. Imaging of pancreatic cancer: an overview. J Gastrointest Oncol 2011;2(3):168-174

35 Andersson R, Vagianos CE, Williamson RC. Preoperative staging and evaluation of resectability in pancreatic ductal adenocarcinoma. HPB (Oxford) 2004;6(1):5-12

36 Takakura K, Sumiyama K, Munakata K, et al. Clinical usefulness of diffusion-weighted MR imaging for detection of pancreatic cancer: comparison with enhanced multidetector-row CT. Abdom Imaging 2011;36(4):457-462

37 Peddu P, Quaglia A, Kane PA, Karani JB. Role of imaging in the management of pancreatic mass. Crit Rev Oncol Hematol 2009;70(1):12-23

38 Lee JK, Kim AY, Kim PN, Lee MG, Ha HK. Prediction of vascular involvement and resectability by multidetector-row $\mathrm{CT}$ versus MR imaging with MR angiography in patients who underwent surgery for resection of pancreatic ductal adenocarcinoma. Eur J Radiol 2010;73(2):310-316

39 Miller FH, Rini NJ, Keppke AL. MRI of adenocarcinoma of the pancreas. AJR Am J Roentgenol 2006;187(4):W365-W374

40 Cuneo KC, Chenevert TL, Ben-Josef E, et al. A pilot study of diffusion-weighted MRI in patients undergoing neoadjuvant chemoradiation for pancreatic cancer. Transl Oncol 2014;7(5):644-649

41 Lin F, Staerkel G. Cytologic criteria for well differentiated adenocarcinoma of the pancreas in fine-needle aspiration biopsy specimens. Cancer 2003;99(1):44-50

42 Siddiqui AA, Brown LJ, Hong SK, et al. Relationship of pancreatic mass size and diagnostic yield of endoscopic ultrasound-guided fine needle aspiration. Dig Dis Sci 2011;56(11):3370-3375

43 Gonçalves B, Soares JB, Bastos P. Endoscopic ultrasound in the diagnosis and staging of pancreatic cancer. GE Port J Gastroenterol 2015;22(4):161-171

44 Gress FG, Hawes RH, Savides TJ, et al. Role of EUS in the preoperative staging of pancreatic cancer: a large single-center experience. Gastrointest Endosc 1999;50(6):786-791

45 Krishna NB, Mehra M, Reddy AV, Agarwal B. EUS/EUS-FNA for suspected pancreatic cancer: influence of chronic pancreatitis and clinical presentation with or without obstructive jaundice on performance characteristics. Gastrointest Endosc 2009;70(1):70-79

46 Bhutani MS, Gress FG, Giovannini M, et al; No Endosonographic Detection of Tumor (NEST) Study. The No Endosonographic Detection of Tumor (NEST) Study: a case series of pancreatic cancers missed on endoscopic ultrasonography. Endoscopy 2004;36(5):385-389 
47 Tio TL, Tytgat GN, Cikot RJ, Houthoff HJ, Sars PR. Ampullopancreatic carcinoma: preoperative TNM classification with endosonography. Radiology 1990;175(2):455-461

48 Grimm H, Maydeo A, Soehendra N. Endoluminal ultrasound for the diagnosis and staging of pancreatic cancer. Baillieres Clin Gastroenterol 1990;4(4):869-888

49 Wakabayashi H, Nishiyama Y, Otani T, et al. Role of 18F-fluorodeoxyglucose positron emission tomography imaging in surgery for pancreatic cancer. World J Gastroenterol 2008;14(1):64-69

50 Pery C, Meurette G, Ansquer C, Frampas E, Regenet N. Role and limitations of 18F-FDG positron emission tomography (PET) in the management of patients with pancreatic lesions. Gastroenterol Clin Biol 2010;34(8-9):465-474

51 Heinrich S, Goerres GW, Schäfer M, et al. Positron emission tomography/computed tomography influences on the management of resectable pancreatic cancer and its cost-effectiveness. Ann Surg 2005;242(2):235-243

52 Kauhanen SP, Komar G, Seppänen MP, et al. A prospective diagnostic accuracy study of $18 \mathrm{~F}$-fluorodeoxyglucose positron emission tomography/computed tomography, multidetector row computed tomography, and magnetic resonance imaging in primary diagnosis and staging of pancreatic cancer. Ann Surg 2009;250(6):957-963

53 Kunstman JW, Fonseca AL, Ciarleglio MM, Cong X, Hochberg A, Salem RR. Comprehensive analysis of variables affecting delayed gastric emptying following pancreaticoduodenectomy. J Gastrointest Surg 2012;16(7):1354-1361

54 McIntyre CA, Winter JM. Diagnostic evaluation and staging of pancreatic ductal adenocarcinoma. Semin Oncol 2015;42(1):19-27

55 Katz MH, Fleming JB, Bhosale $\mathrm{P}$, et al. Response of borderline resectable pancreatic cancer to neoadjuvant therapy is not reflected by radiographic indicators. Cancer 2012;118(23):5749-5756

56 Katz MH, Pisters PW, Evans DB, et al. Borderline resectable pancreatic cancer: the importance of this emerging stage of disease. J Am Coll Surg 2008;206(5):833-846

$57 \mathrm{Kim} \mathrm{CB}$, Ahmed S, Hsueh EC. Current surgical management of pancreatic cancer. J Gastrointest Oncol 2011;2(3): 126-135

58 Tran KT, Smeenk HG, van Eijck $\mathrm{CH}$, et al. Pylorus preserving pancreaticoduodenectomy versus standard Whipple procedure: a prospective, randomized, multicenter analysis of 170 patients with pancreatic and periampullary tumors. Ann Surg 2004;240(5):738-745

59 Whipple AO, Parsons WB, Mullins CR. Treatment of carcinoma of the ampulla of Vater. Ann Surg 1935;102(4):763-779

60 Goh BK, Tan YM, Chung YF, et al. Critical appraisal of 232 consecutive distal pancreatectomies with emphasis on risk factors, outcome, and management of the postoperative pancreatic fistula: a 21-year experience at a single institution. Arch Surg 2008;143(10):956-965

61 Wolfgang CL, Corl F, Johnson PT, et al. Pancreatic surgery for the radiologist, 2011: an illustrated review of classic and newer surgical techniques for pancreatic tumor resection. AJR Am J Roentgenol 2011;197(6):1343-1350

62 Abrams RA, Lowy AM, O'Reilly EM, Wolff RA, Picozzi VJ, Pisters PW. Combined modality treatment of resectable and borderline resectable pancreas cancer: expert consensus statement. Ann Surg Oncol 2009;16(7):1751-1756

63 Suker M, Beumer BR, Sadot E, et al. FOLFIRINOX for locally advanced pancreatic cancer: a systematic review and patient-level meta-analysis. Lancet Oncol 2016;17(6):801-810

64 Roeder F. Neoadjuvant radiotherapeutic strategies in pancreatic cancer. World J Gastrointest Oncol 2016;8(2):186-197

65 Dalah E, Tai A, Oshima K, Hall WA, Erickson B, Li XA. PETbased treatment response assessment for neoadjuvant chemoradiation in pancreatic adenocarcinoma: an exploratory study. Transl Oncol 2018;11(5):1104-1109

66 Adsay NV. Cystic neoplasia of the pancreas: pathology and biology. J Gastrointest Surg 2008;12(3):401-404

67 Tanaka M, Chari S, Adsay V, et al; International Association of Pancreatology. International consensus guidelines for management of intraductal papillary mucinous neoplasms and mucinous cystic neoplasms of the pancreas. Pancreatology 2006;6(1-2):17-32

68 Pelaez-Luna M, Chari ST, Smyrk TC, et al. Do consensus indications for resection in branch duct intraductal papillary mucinous neoplasm predict malignancy? A study of 147 patients. Am J Gastroenterol 2007;102(8):1759-1764

69 Takasu N,KimuraW, Moriya T, etal.Intraductal papillary-mucinous neoplasms of the gastric and intestinal types may have less malignant potential than the pancreatobiliary type. Pancreas 2010;39(5):604-610

70 Kallen ME, Naini BV. Intraductal oncocytic papillary neoplasms of the pancreas. Arch Pathol Lab Med 2016;140(9):992-996

71 Salvia R, Fernández-del Castillo C, Bassi C, et al. Main-duct intraductal papillary mucinous neoplasms of the pancreas: clinical predictors of malignancy and long-term survival following resection. Ann Surg 2004;239(5):678-685, discussion 685-687

72 Rodriguez JR, Salvia R, Crippa S, et al. Branch-duct intraductal papillary mucinous neoplasms: observations in 145 patients who underwent resection. Gastroenterology 2007;133(1):72-79

73 Machado NO, Al Qadhi H, Al Wahibi K. Intraductal papillary mucinous neoplasm of pancreas. $\mathrm{N}$ Am J Med Sci 2015;7(5):160-175

74 Song SJ, Lee JM, Kim YJ, et al. Differentiation of intraductal papillary mucinous neoplasms from other pancreatic cystic masses: comparison of multirow-detector CT and MR imaging using ROC analysis. J Magn Reson Imaging 2007;26(1):86-93

75 Manfredi R, Graziani R, Motton M, et al. Main pancreatic duct intraductal papillary mucinous neoplasms: accuracy of MR imaging in differentiation between benign and malignant tumors compared with histopathologic analysis. Radiology 2009;253(1):106-115

76 Procacci C, Megibow AJ, Carbognin G, et al. Intraductal papillary mucinous tumor of the pancreas: a pictorial essay. Radiographics 1999;19(6):1447-1463

77 Salvia R, Crippa S, Falconi M, et al. Branch-duct intraductal papillary mucinous neoplasms of the pancreas: to operate or not to operate? Gut 2007;56(8):1086-1090

78 Chandwani R, Allen PJ. Cystic neoplasms of the pancreas. Annu Rev Med 2016;67(1):45-57

79 Crippa S, Salvia R, Warshaw AL, et al. Mucinous cystic neoplasm of the pancreas is not an aggressive entity: lessons from 163 resected patients. Ann Surg 2008;247(4):571-579

80 Falconi M, Bartsch DK, Eriksson B, et al; Barcelona Consensus Conference participants. ENETS Consensus Guidelines for the management of patients with digestive neuroendocrine neoplasms of the digestive system: well-differentiated pancreatic non-functioning tumors. Neuroendocrinology 2012;95(2):120-134

81 Yao JC, Hassan M, Phan A, et al. One hundred years after "carcinoid": epidemiology of and prognostic factors for neuroendocrine tumors in 35,825 cases in the United States. J Clin Oncol 2008;26(18):3063-3072

82 Bosman FT, Carneiro F, Hruban R H, Theise N. WHO Classification of Tumours of the Digestive System. 4th ed. France: IARC; 2010

83 Rodallec M, Vilgrain V, Couvelard A, et al. Endocrine pancreatic tumours and helical CT: contrast enhancement is correlated with microvascular density, histoprognostic factors and survival. Pancreatology 2006;6(1-2):77-85 
84 Horton KM, Hruban RH, Yeo C, Fishman EK. Multi-detector row CT of pancreatic islet cell tumors. Radiographics 2006;26(2):453-464

85 Katsuta E, Kudo A, Akashi T, et al. Macroscopic morphology for estimation of malignant potential in pancreatic neuroendocrine neoplasm. J Cancer Res Clin Oncol 2016;142(6):1299-1306

86 Ichikawa T, Peterson MS, Federle MP, et al. Islet cell tumor of the pancreas: biphasic CT versus MR imaging in tumor detection. Radiology 2000;216(1):163-171

87 Sundin A, Vullierme MP, Kaltsas G, Plöckinger U. Mallorca Consensus Conference participants; European Neuroendocrine Tumor Society. ENETS Consensus Guidelines for the Standards of Care in Neuroendocrine Tumors: radiological examinations. Neuroendocrinology 2009;90(2):167-183

88 Thoeni RF, Mueller-Lisse UG, Chan R, Do NK, Shyn PB. Detection of small, functional islet cell tumors in the pancreas: selection of MR imaging sequences for optimal sensitivity. Radiology 2000;214(2):483-490
89 James PD, Tsolakis AV, Zhang M, et al. Incremental benefit of preoperative EUS for the detection of pancreatic neuroendocrine tumors: a meta-analysis. Gastrointest Endosc 2015;81(4):848-856

90 Hofman MS, Kong G, Neels OC, Eu P, Hong E, Hicks RJ. High management impact of Ga-68 DOTATATE (GaTate) PET/CT for imaging neuroendocrine and other somatostatin expressing tumours. J Med Imaging Radiat Oncol 2012;56(1):40-47

91 Busquets J, Ramírez-Maldonado E, Serrano T, et al. Surgical treatment of non-functioning pancreatic neuroendocrine tumours based on three clinical scenarios. Cir Esp 2016;94(10):578-587

92 Perry RR, Vinik AI. Clinical review 72: diagnosis and management of functioning islet cell tumors. J Clin Endocrinol Metab 1995;80(8):2273-2278 